FAKTOR RISIKO KEJADIAN HIPERTENSI PADA USIA 20-44 TAHUN DI PUSKESMAS KAWATUNA KOTA PALU

\title{
Risk Factors of Hypertension Adult 20-44 Years at Community Health Center of Kawatuna, City of Palu
}

\author{
Ayu Astari Puspitasari* 1 \\ ${ }^{1 .}$ Bagian Gizi Kesehatan Masyarakat, Fakultas Kesehatan Masyarakat Universitas Tadulako
}

Diterima: 24 November 2018; Revisi: 06 Desember 2018; Diterbitkan: 31 Desember 2018

\section{Abstract}

Background \& Objective: Hypertension is a serious public health problem that closes to a high prevalence. It has already killed 1.5 million people every year in South East Asia. Public health centre Kawatuna is public health centre which has the highest prevalence in 2006 from 13 public health centers in Palu. The study aims at finding out the habit of consuming fruits and vegetables, habit of consuming coffee, habit of smoking and BMI (Body Mass Index) as a risk factor of hypertension occurrence in the age of 20-44 years old in Public Health Centre Kawatuna Palu Material and Methods: This was a case control study. Sample drawn for case group used total sampling whereas for control group used purposive sampling. Results: Consumption of fruits and vegetables was a risk factor for hypertension $(\mathrm{OR}=3,381$ $(1,840-6,214))$, coffee consumption was a risk factor for hypertension $(\mathrm{OR}=2,234(1,102-4,532))$, BMI was a risk factor for hypertension $(\mathrm{OR}=3,474(1,820-6,629))$ and smoking habits are risk factors for hypertension but not significant $(\mathrm{OR}=1,725(0,680-4,380))$. Conclusion: Habit of lack of consuming fruit and vegetable, habit of over consuming coffee and IMT $>25 \mathrm{~kg} / \mathrm{m}^{2}$ are the risk factors of hypertension occurrence .

Keywords: Hypertension, Fruit and Vegetable, Coffee, Smoking, BMI

\begin{abstract}
Abstrak
Latar Belakang \& Tujuan : Hipertensi merupakan masalah kesehatan masyarakat serius yang mendekati prevalensi tinggi. Penyakit hipertensi telah membunuh 1,5 juta orang setiap tahunnya di Asia Tenggara. Puskesmas Kawatuna merupakan puskesmas yang memiliki prevalensi hipertensi tertinggi pada tahun 2016 dari 13 puskesmas yang ada di Kota Palu. Tujuan penelitian ini untuk mengetahui kebiasaan mengonsumsi buah dan sayur, kebiasaan mengonsumsi kopi, kebiasaan merokok dan IMT (Indeks Massa Tubuh) sebagai faktor risiko kejadian hipertensi pada usia 20-44 tahun di Puskesmas Kawatuna Kota Palu. Bahan dan Metode : Jenis penelitian ini adalah case control study. Pengambilan sampel untuk kelompok kasus menggunakan teknik total sampling sedangkan untuk kelompok kontrol menggunakan teknik purposive sampling. Analisis yang digunakan adalah analisis univariat dan analisis bivariat Hasil: Kebiasaan mengonsumsi buah dan sayur merupakan faktor risiko kejadian hipertensi $(\mathrm{OR}=3,381(1,840$ 6,214)), kebiasaan mengonsumsi kopi merupakan faktor risiko kejadian hipertensi (OR = 2,234 $(1,102-4,532)$ ), IMT merupakan faktor risiko kejadian hipertensi $(\mathrm{OR}=3,474(1,820-6,629))$ dan kebiasaan merokok merupakan faktor risiko kejadian hipertensi namun tidak bermakna $(\mathrm{OR}=1,725(0,680-4,380))$. Kesimpulan : Kebiasaan kurang mengonsumsi buah dan sayur, kebiasaan mengonsumsi kopi berlebih dan IMT $>25 \mathrm{~kg} / \mathrm{m}^{2}$ merupakan faktor risiko kejadian hipertensi.
\end{abstract}

Kata Kunci: Hipertensi, Buah dan Sayur, Kopi, Merokok, IMT

*Korespondensi: Email : ayu13_kesmas_b@yahoo.com

\section{PENDAHULUAN}

Pada tahun 2008, secara global keseluruhan prevalensi tekanan darah tinggi pada orang dewasa berusia $\geq 25$ tahun adalah sekitar $40 \%$. Prevalensi hipertensi tertinggi terdapat di wilayah Afrika yaitu $46 \%$ pada orang dewasa berusia $\geq 25$ tahun. Secara keseluruhan, negara-negara berpenghasilan tinggi memiliki prevalensi hipertensi lebih rendah yaitu $35 \%$ dari kelompok lain yaitu 40\% (WHO, 2011a). Penyakit hipertensi telah membunuh 1,5 juta orang setiap ta- hunnya di Asia Tenggara (WHO, 2011b).

Riskesdas tahun 2013 menunjukkan prevalensi rata-rata hipertensi di Indonesia sebesar 25,8\%. Hasil survei dari 33 Provinsi di Indonesia menunjukkan terdapat 8 provinsi yang mempunyai prevalensi hipertensi melebihi rata-rata nasional. Prevalensi hipertensi tertinggi pertama yaitu berada di Bangka Belitung sebesar 30,90\% dan Sulawesi Tengah berada di posisi ke-enam yaitu sebesar 28,70\% (Kemenkes RI, 2014). 
Pada tahun 2013, 2014 dan 2015, penderita hipertensi di Sulawesi Tengah sebanyak 37.615 jiwa, 69.521 jiwa dan 96.797 jiwa (Dinkes Sulteng, 2013, 2014, 2015). Puskesmas Kawatuna merupakan salah satu puskesmas yang terdapat di Kota Palu dengan prevalensi hipertensi pertama tertinggi pada tahun 2016 yaitu sebesar 12,3\%. Berdasarkan data Puskesmas Kawatuna Kota Palu, semenjak tahun 2013 hingga ke tahun 2014 telah terjadi peningkatan kasus hipertensi sebesar $8,08 \%$, lalu dari tahun 2014 ke tahun 2015 meningkat sebesar 6,77\% dan dari tahun 2015 ke tahun 2016 meningkat sebesar 31,26\%.

Penelitian ini bertujuan untuk menganalisis faktor risiko kejadian hipertensi pada usia 20-44 Tahun di Puskesmas Kawatuna Kota Palu

\section{BAHAN DAN METODE}

\subsection{Jenis Penelitian}

Jenis penelitian menggunakan Survey Analitik dengan pendekatan Case Control yang dilaksanakan di Puskesmas Kawatuna pada tahun 2017

\subsection{Sampel Penelitian}

Jumlah sampel yaitu sebanyak 188 responden dengan perbandingan 1:1. Pengambilan sampel kasus menggunakan teknik total sampling dan sampel kontrol menggunakan teknik purposive sampling .

\subsection{Pengumpulan Data}

Pengumpulan data melalui observasi langsung, wawancara, kuesioner dan data dari instansi terkait. Kebiasaan mengonsumsi buah dan sayur menggunakan kuesioner FFQ-Semikuantatif yang berisikan daftar buah dan sayur. Indeks massa tubuh (IMT) dilakukan pengukuran secara langsung dengan menggunakan timbangan digital dan microtoise.

\subsection{Analisis Data}

Analisis data penelitian menggunakan uji odd ratio dengan tingkat kemaknaan $5 \%$ dan derajat kepercayaan (CI) $95 \%$.

\section{HASIL}

Hasil analisis Odds Ratio (OR) dengan Confidence Interval (CI) 95\% menunjukkan adanya risiko kebiasaan kurang mengonsumsi buah dan sayur terhadap kejadian hipertensi OR $=2,234$ (1,102-4,532), kebiasaan merokok berat terhadap kejadian hipertensi OR = 1,725 (0,680-4,380) dan gemuk/obesitas terhadap kejadian hipertensi OR $=3,474(1,820-6,629)$ (Tabel 1).

\section{PEMBAHASAN}

Kebiasaan Mengonsumsi Buah dan Sayur

Peningkatan konsumsi buah dan sayur merupakan salah satu upaya dalam mencegah dan membantu mengobati hipertensi. Salah satu diet hipertensi yaitu diet DASH (Dieatary Approaches to Stop Hypertension) telah menganjurkan agar lebih banyak mengonsumsi buah dan sayur karena banyak mengandung mineral penting seperti kalium, magnesium dan serat sehingga tekanan darah tetap normal (Julianti, 2008). Hasil penelitian diperoleh bahwa kebiasaan kurang mengonsumsi buah dan sayur merupakan faktor risiko kejadian hipertensi dengan nilai OR yaitu 3,381 (1,8406,214).

Hal ini menunjukkan bahwa kebiasaan kurang mengonsumsi buah dan sayur berisiko 3,381 kali lebih besar untuk menderita hipertensi dibandingkan dengan kebiasaan cukup mengonsumsi buah dan sayur.

Penelitian ini sejalan dengan penelitian Helelo et al (2014) bahwa orang dewasa yang tidak mengonsumsi sayur $>3$ hari dalam menu makanan mingguan mereka selama dua kali berturut-turut berisiko 52,30 kali lebih besar menderita hipertensi dari mereka yang mengonsumsi sayuran setiap harinya. Hasil penelitian ini juga sejalan dengan penelitian Gebrihet et al (2017) memperoleh nilai OR $=4,31(1,74-10,66)$.

\section{Tabel 1. Analisis Faktor Risiko Kejadian Hipertensi Pada Usia 20-44 Tahun di Puskesmas Kawatuna} Kota Palu

\begin{tabular}{|c|c|c|c|c|c|}
\hline \multirow{3}{*}{ Variabel } & \multicolumn{4}{|c|}{ Hipertensi } & \multirow{3}{*}{$\begin{array}{c}\text { OR } \\
\text { CI 95\% }\end{array}$} \\
\hline & \multicolumn{2}{|c|}{ Kasus } & \multicolumn{2}{|c|}{ Kontrol } & \\
\hline & $\mathrm{n}$ & $\%$ & $\mathrm{n}$ & $\%$ & \\
\hline \multicolumn{6}{|l|}{ Kebiasaan Mengonsumsi Buah dan Sayur } \\
\hline Kebiasaan Kurang Mengonsumsi Buah dan Sayur (<400 gr/hari) & 68 & 72,3 & 41 & 43,6 & \multirow{2}{*}{$\begin{array}{c}3,381 \\
(1,840-6,214)\end{array}$} \\
\hline $\begin{array}{l}\text { Kebiasaan Cukup Mengonsumsi Buah dan Sayur (400-600 } \\
\text { gr/hari) }\end{array}$ & 26 & 27,7 & 53 & 56,4 & \\
\hline \multicolumn{6}{|l|}{ Kebiasaan Mengonsumsi Kopi } \\
\hline $\begin{array}{l}\text { Kebiasaan Mengonsumsi Kopi Berlebih ( } \geq 3 \text { sdm kopi dan } \geq 6 \text { kali } \\
\text { seminggu) }\end{array}$ & 28 & 65,1 & 15 & 34,9 & \multirow{2}{*}{$\begin{array}{c}2,234 \\
(1,102-4,532)\end{array}$} \\
\hline $\begin{array}{l}\text { Kebiasaan Mengonsumsi Kopi Cukup ( }<3 \text { sdm kopi dan }<6 \text { kali } \\
\text { seminggu) }\end{array}$ & 66 & 45,5 & 79 & 54,5 & \\
\hline \multicolumn{6}{|l|}{ Kebiasaan Merokok } \\
\hline Berat ( $\geq 10$ batang/hari) & 13 & 13,8 & 8 & 8,5 & \multirow{2}{*}{$\begin{array}{c}1,725 \\
(0,680-4,380)\end{array}$} \\
\hline Ringan $(<10$ batang/hari) & 81 & 86,2 & 86 & 91,5 & \\
\hline \multicolumn{6}{|l|}{ IMT } \\
\hline Gemuk/Obesitas $\left(>25 \mathrm{~kg} / \mathrm{m}^{2}\right)$ & 44 & 46,8 & 19 & 20,2 & \multirow{2}{*}{$\begin{array}{c}3,474 \\
(1,820-6,629)\end{array}$} \\
\hline Normal $\left(18,5-25 \mathrm{~kg} / \mathrm{m}^{2}\right)$ & 50 & 53,2 & 75 & 79,8 & \\
\hline
\end{tabular}




\section{Kebiasaan Mengonsumsi Kopi}

Konsumsi kopi merupakan faktor risiko terjadinya hipertensi. Kopi berbahaya bagi penderita hipertensi karena mengandung suatu senyawa yaitu kafein yang dapat meningkatkan tekanan darah. Penderita hipertensi dianjurkan untuk menghindari konsumsi kopi (Insan, 2016). Hasil penelitian diperoleh bahwa kebiasaan mengonsumsi kopi berlebih merupakan faktor risiko kejadian hipertensi dengan nilai OR yaitu 2,234 $(1,102-4,532)$. Hal ini menunjukkan bahwa kebiasaan mengonsumsi kopi berlebih, berisiko 2,234 kali lebih besar untuk menderita hipertensi dibandingkan dengan kebiasaan mengonsumsi kopi cukup.

Penelitian ini sejalan dengan penelitian Elvivin et al (2016) memperoleh nilai OR = 12,5 (4,883-31,999). Begitupula pada penelitian Hadi (2016) yang menyatakan bahwa kebiasaan minum kopi berisiko hipertensi 2,103 kali lebih besar dibandingkan dengan tidak memiliki kebiasaan minum kopi. Namun, berbeda dengan hasil penelitian yang dilakukan oleh Ruus et al (2016) memperoleh hasil bahwa tidak terdapat hubungan antara konsumsi kopi dengan kejadian hipertensi.

\section{Kebiasaan Merokok}

Merokok merupakan salah satu faktor risiko hipertensi yang dapat diubah. Hal ini terjadi melalui mekanisme pelepasan norepinefrin dari ujung-ujung saraf adrenergik yang dipacu oleh nikotin. Seseorang yang merokok lebih dari satu pak per hari memiliki kerentanan dua kali lebih besar menderita hipertensi jika dibandingkan dengan yang tidak merokok (Kurniadi dan Nurrahmi, 2014). Hasil penelitian diperoleh bahwa kebiasaan merokok berat merupakan faktor risiko kejadian hipertensi yang tidak memiliki hubungan bermakna dengan nilai OR yaitu $1,725(0,680-4,380)$. Hal ini menunjukkan bahwa kebiasaan merokok berat, berisiko 1,725 kali lebih besar untuk menderita hipertensi dibandingkan dengan kebiasaan merokok ringan.

Penelitian ini sejalan dengan penelitian Heriziana (2017) yang menunjukkan bahwa kebiasaan merokok merupakan faktor risiko kejadian hipertensi dengan nilai $\mathrm{OR}=1,472(1,073-2,018)$ yang berarti seseorang yang memiliki kebiasaan merokok berisiko 1,472 kali lebih besar menderita hipertensi dibandingkan dengan seseorang yang tidak merokok. Hasil penelitian yang tidak sejalan ditemukan pada penelitian Aripin et al (2015) memperoleh nilai OR $=0,58(0,18-1,86)$.

\section{IMT}

Kenaikan berat badan yang berlebih merupakan salah satu penyebab terjadinya hipertensi. Seseorang yang mengalami obesitas memerlukan oksigen yang lebih banyak untuk membantu dalam proses pembakaran kalori dalam tubuh. Pada saat proses ini berlangsung, jantung akan bekerja lebih keras dari biasanya sehingga berakibat pada peningkatan tekanan darah yang memicu terjadinya hipertensi (Widharto, 2007) Hasil penelitian diperoleh bahwa IMT $>25 \mathrm{~kg} / \mathrm{m}^{2}$ (gemuk/obesitas) merupakan faktor risiko kejadian hipertensi dengan nilai OR yaitu 3,474 $(1,820-6,629)$. Hal ini menunjukkan bahwa IMT $>25 \mathrm{~kg} / \mathrm{m}^{2}$ (gemuk/ obesitas) berisiko 3,474 kali lebih besar untuk menderita hipertensi dibandingkan dengan IMT 18,5-25 $\mathrm{kg} / \mathrm{m}^{2}$ (normal).
Hasil penelitian ini sejalan dengan penelitian yang dilakukan oleh Fitriana et al (2013), memperoleh nilai $\mathrm{OR}=12,32$ yang berarti bahwa responden yang obesitas berisiko 12,32 kali lebih besar dibandingkan dengan responden yang tidak obesitas. Begitu pula pada penelitian yang dilakukan oleh Faisal et al (2012) dengan nilai $\mathrm{OR}=4,67(2,239-10,903)$.

\section{E. KESIMPULAN}

Kebiasaan kurang mengonsumsi buah dan sayur ( $<400$ gr/hari), kebiasaan mengonsumsi kopi berlebih ( $\geq 3$ sdm kopi dan $\geq 6$ kali seminggu), kebiasaan merokok berat dan IMT $>25 \mathrm{~kg} / \mathrm{m}^{2}$ (gemuk/obesitas) merupakan faktor risiko kejadian hipertensi pada usia 20-44 tahun di Puskesmas Kawatuna Kota Palu. Masyarakat sebaiknya mengonsumsi buah dan sayur sesuai dengan yang telah dianjurkan yaitu 400 gr/hari (2 porsi sayur dan 3 porsi buah), mengontrol kenaikan berat badan agar tidak mengalami kegemukan/obesitas (IMT $>25$ $\mathrm{kg} / \mathrm{m}^{2}$ ), mengonsumsi kopi $<3 \mathrm{sdm}$ dan $<6$ kali dalam seminggu, serta berhenti merokok. Hal ini merupakan bentuk pencegahan agar terhindar dari penyakit serta bertujuan untuk mewujudkan derajat kesehatan masyarakat yang optimal

\section{F. DAFTAR PUSTAKA}

Aripin, Sawitri, A.A.S. dan Adiputra, N. 2015. 'Faktor Risiko Kejadian Hipertensi Pada Orang Dewasa di Banyuwangi : Studi Kasus Kontrol', Public Health and Preventive Medicine Archieve, 3(2), pp. 141-149.

Dinkes Sulteng. 2013. Cakupan Pengukuran Tekanan Darah Menurut Jenis Kelamin, Kabupaten/ Kota dan Puskesmas Provinsi Sulawesi Tengah Tahun 2013. Palu.

Dinkes Sulteng. 2014. Pengukuran Tekanan Darah Penduduk $\geq 18$ Menurut Jenis Kelamin, Kabupaten/Kota, dan Puskesmas Provinsi Sulawesi Tengah Tahun 2014. Palu.

Dinkes Sulteng. 2015. Pengukuran Tekanan Darah Penduduk $\geq 18$ Menurut Jenis Kelamin, Kabupaten/Kota, dan Puskesmas. Palu.

Elvivin, Lestari, H. dan Ibrahim, K., 2016. 'Analisis Faktor Risiko Kebiasaan Mengkonsumsi Garam, Alkohol, Kebiasaan Merokok dan Minum Kopi Terhadap Kejadian Hipertensi Pada Nelayan Suku Bajo di Pulau Tasipi Kabupaten Muna Barat Tahun 2015', Jurnal Ilmiah Mahasiswa Kesehatan Masyarakat, 1 (3), pp. 1-12.

Faisal, E., Djarwoto, B. dan Murtiningsih, B. 2012. 'Faktor Risiko Hipertensi Pada Wanita Pekerja Dengan Peran Ganda Kabupaten Bantul Tahun 2011', Berita Kedokteran Masyarakat, 28(2), pp. 55-62.

Fitriana, R., Lipoeto, N.I. dan Triana, V. 2013. 'Faktor Risiko Kejadian Hipertensi Pada Remaja di Wilayah Kerja Puskesmas Rawat Inap Sidomulyo Kota Pekanbaru', Jurnal Kesehatan Masyarakat, 7(1), pp. 10-15.

Gebrihet, T.A., Mesgna, K.H., Gebregiorgis, Y.S., Kahsay, A.B., Weldehaweria, N.B. dan Weldu, M.G. 2017. 'Awareness, Treatment, and Control of Hypertension is Low Among Adults in Aksum Town, Northern Ethiopia: A Sequential Quantitative-Qualitative Study', PLoS ONE, 12(5), pp. 1-16. 
Hadi, Z. 2016. 'Hubungan Kebiasaan Minum Kopi dan Minum-Minuman Keras Dengan Kejadian Hipertensi di Puskesmas Kelayan Timur Banjarmasin Tahun 2015', An Nadaa Jurnal Ilmiah Kesehatan Masyarakat, 3(1), pp. 6-9.

Helelo, T.P., Gelaw, Y.A. dan Adane, A.A. 2014. 'Prevalence and Associated Factors of Hypertension among Adults in Durame Town, Southern Ethiopia', PLoS ONE, 9(11), pp.1-9.

Heriziana. 2017. 'Faktor Resiko Kejadian Penyakit Hipertensi di Puskesmas Basuki Rahmat Palembang', Jurnal Kesmas Jambi, 1(1), pp. 31 -39 .

Insan, A.N.M. dan Kurniawaty, E. 2016. 'Pengaruh Kopi Terhadap Hipertensi', Majority, 5(2), pp. 6-10.

Julianti, E.D., Nurjanah, N. dan Soetrisno, U.S.S. 2008. Bebas Hipertensi dengan Terapi Jus. Jakarta: Niaga Swadaya.

Kemenkes RI. 2013. Riset Kesehatan Dasar 2013. Jakarta: Kementerian Kesehatan Republik Indonesia.

Kurniadi, H. dan Nurrahmi, U. 2014. Stop! Diabetes, Hipertensi, Kolesterol Tinggi, Jantung Koroner, Yogyakarta: Istana Media.

Ruus, M., Kepel, B.J. dan Umboh, J.M.L. 2016. 'Hubungan Antara Konsumsi Alkohol dan Kopi Dengan Kejadian Hipertensi Pada Laki-Laki di Desa Ongkaw Dua Kecamatan Sinosayang Kabupaten Minahasa Selatan', Jurnal KESMAS, 5(1), pp. 66-72.

WHO. 2011a. Global Status Report on Noncomunicable Diseases 2010. Italy: World Health Organization.

WHO. 2011b. Noncommunicable Diseases in The South-East Asia Region: Situation and Response 2011. India: World Health Organization.

Widharto. 2007. Bahaya Hipertensi. Jakarta: PT Sunda Kelapa Pustaka. 